pressure was 120 , pulse 75 per minute and temperature noted to be $38^{\circ} \mathrm{C}$. The calibration of the temperature monitor was checked and a new battery was installed. Fifteen minutes after induction, the temperature was $39^{\circ} \mathrm{C}$ and still rising. Halothane was discontinued, preparations were begun for doing arterial blood gases and the "Malignant Hyperthermia" protocol was called for. However, because the pulse was still low at $75 / \mathrm{min}$, the probe itself was checked. A rectal probe was being used in the axilla and a small $I x$ $2 \mathrm{~mm}$ piece of white coating over the thermocouple had been chipped off. A new probe gave a reading of $35^{\circ} \mathrm{C}$. Halothane was reinstituted and the rest of the operation and recovery were uneventful.

Apparently, the chipped temperature probe allowed water to enter the thermocouple slowly. This probably reduced the electrical resistance and so the temperature monitor recorded a continuous rise in temperature.

A notice on the back of the temperature monitor notes that defective probes may cause off-scale readings but makes no mention of a continuously rising temperature pattern.

The case is instructive because it reminds us that there are many causes of hyperthermia in the operating room. The temperature rise in malignant hyperthermia is secondary to an increased metabulic rate. Therefore, malignant hyperthermia is usually associated with tachycardia, arrhy thmia, cyanosis, and lactic acidosis. The lack of such signs in this case allowed us to concentrate on technical problems. However, if the patient had had a tachycardia for other reasons, treatment for malignant hyperthermia might have been instituted prematurely, since the slow continuous increase in the temperature reading was very disturbing.

A.O. Davies, M.D., F.R.C.P.(C)

\section{Closed Circuit Operation of Bain Circuit}

SIR,

With reference to the paper the "D Circle: Closed-Circuit Operation Of The Bain Circuit" (F.J. Sasse et al., 1979), ${ }^{1}$ we would like to draw attention to a similar circuit employing another principle for reduction of the fresh gas requirement.

A diagram of the circuit is shown in the figure. The fresh gas is conveyed through an injector unit (1) to the co-axial tubing (2). A $600 \mathrm{~g}$ canister (3) ${ }^{2}$

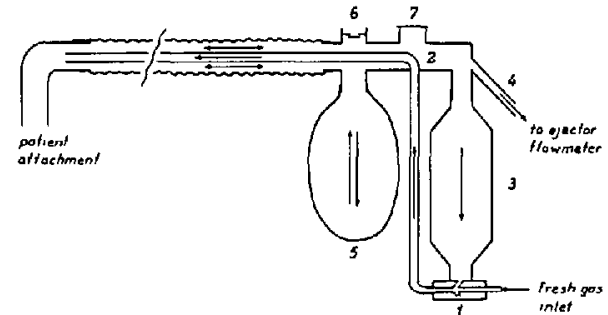

Figure I

is placed at the entrainment part of the injector. The expired gas is partly evacuated directly from the circuit (4) by means of an ejector flowmeter ${ }^{3}$ and partly recirculated through the canister. This is made possible by means of the negative pressure created by the fresh gas flow around the injector jet. Negative and positive pressure relief valves $(6,7)$ placed downstream between the breathing bag (5) and the canister. Our investigations show that the negative pressure around the injector jet is sufficient to recirculate a gas volume of approximately 165 per cent of the fresh gas flow during controlled ventilation. A fresh gas flow of $31 / \mathrm{min}$ results in a total carbon dioxidefree gas flow at the patient attachment of $81 / \mathrm{min}$; at a fresh gas flow of $41 / \mathrm{min}$. the patient will receive approximately $111 / \mathrm{min}$. The flows were measured using suitable soapbubble burettes; ${ }^{4}$ following correction for the vapour pressure of water, the calculated flows were corrected to $20^{\circ} \mathrm{C}, 760 \mathrm{~mm} \mathrm{Hg}$.

A considerable reduction of the fresh gas requirement is obtained by converting a Mapleson $\mathrm{D}$ (Bain) circuit to closed-circuit operation in this way. The employment of a pump is omitted and the associated possibilities of inconvenience and malfunction are removed.

Jens Waaben

Søren Jørgensen

\section{ReFERENCES}

1. Sasse. F.J., Flemming, D.C., Hoff, B., Ty. SMITH, N \& Rampal, IJ. The "D Circle": Closed-Circuit Operation of The Bain Circuit. Canad. Anaesth. Soc. J. 26: 420 (1979).

2. JøRGENSEN, B. \& JøRGensen, S. The 600-gram $\mathrm{CO}_{2}$ absorption canister: an experimental study. Acta. anaesth. scand. 21: 437 (1977).

3. JoRGENSEN. S. The ejector flowmeter and its clinical application. Acta anaesth. scand. 18: 29 (1974).

4. LEVY, A. The accuracy of the bubble meter method for gas flow measurements. J. Sci. Instrum. 4I: 449 (1964) 